\title{
Development and validation of a UHPLC-UV method for the detection and quantification of erectile dysfunction drugs and some of their analogues found in counterfeit medicines.
}

\author{
Pierre-Yves Sacré ${ }^{a, b}$, Eric Deconinck ${ }^{a}$, Patrice Chiap ${ }^{c}$, Jacques Crommen ${ }^{b}$, François \\ Mansion $^{\mathrm{b}}$, Eric Rozet ${ }^{\mathrm{d}}$, Patricia Courselle ${ }^{\mathrm{a}}$, Jacques O. De Beer ${ }^{\mathrm{a},{ }^{*}}$ \\ a Laboratory of Drug Analysis, Scientific Institute of Public Health, Brussels, Belgium \\ ${ }^{b}$ Department of Analytical Pharmaceutical Chemistry, Institute of Pharmacy, University of Liège, Liège, Belgium. \\ ${ }^{c}$ Advanced Technology Corporation (A.T.C.), University Hospital of Liège, Liège, Belgium \\ ${ }^{d}$ Department of Analytical Chemistry, Institute of Pharmacy, University of Liège, Liège, Belgium.
}

\begin{abstract}
Pharmaceutical counterfeiting is a permanently growing problem. Control laboratories are constantly analysing counterfeit medicines. In industrialised countries, one of the main counterfeited class of medicines are erectile dysfunction drugs. This paper describes the development and validation of a fast method to detect and quantify the three authorised phosphodiesterase type 5 inhibitors and five analogues. The method is based on the use of a sub-2 microns polar-embedded column with a gradient using acetonitrile as organic modifier and $10 \mathrm{mM}$ ammonium formate buffer ( $\mathrm{pH} \mathrm{3.5)}$ as aqueous component of the mobile phase. The separation was achieved in less than $4.5 \mathrm{~min}$. The method has also been compared to the registered HPLC method for the assay of Viagra ${ }^{\circledR}$ which was considered as the reference method.

The method is also compatible with on-line coupling mass spectrometry and will significantly reduce analysis times and solvent consumption.
\end{abstract}

Keywords:

Phosphodiesterase type 5 inhibitors; UHPLC; method validation, analogues, counterfeit drugs, accuracy profiles.

*Corresponding Author. Tel.: +32 264251 70; Fax: +32 26425327

E-mail address: jacques.debeer@wiv-isp.be

Address: IPH-Drug analysis, Dr J. De Beer, Rue Juliette Wytsmanstraat 14, 1050 Brussels 


\section{Introduction}

The number of cases of pharmaceutical counterfeiting is constantly growing since the first cases were detected in the early 90's [1]. In industrialised countries, one of the most counterfeited classes of medicines is the phosphodiesterase type 5 inhibitors (PDE5-i) [2]. Among them only three drugs are approved and marketed: sildenafil citrate (Pfizer), tadalafil (Eli Lilly) and vardenafil hydrochloride (Bayer). These drugs are used in erectile dysfunction disorders (Viagra ${ }^{\circledR}$, Cialis ${ }^{\circledR}$ and Levitra ${ }^{\circledR}$ ). Sildenafil citrate is also used in pulmonary arterial hypertension (Revatio ${ }^{\circledR}$ ).

Due to the taboo associated with erectile dysfunction, PDE5-inhibitors are widely sold over the internet as both counterfeited medicines and illegal adulterants in herbal dietary supplements. In the latter the biggest diversity of analogues was found [2-4]. For this study, three analogues of sildenafil (acetildenafil, hydroxyacetildenafil and dimethylsildenafil), one of vardenafil (pseudovardenafil), one of tadalafil (aminotadalafil) and the bioactive diastereoisomer of tadalafil (trans-tadalafil) have been chosen. Their chemical structures are shown in Figure 1. These compounds are representative of what is commonly found in illegal preparations.

All of these analogues have already been found in illegal preparations. These preparations have been analysed using different analytical systems (LC-UV, LC-MS, IR, NMR, X-ray diffraction, etc.) [5-28]. The presented validated method allows a fast separation and quantification of the three authorised PDE5-i and five of their analogues. This method may constitute a good basis for the analysis of illegal erectile dysfunction medicines by official control laboratories.

The present paper describes a method enabling the separation and quantification of nine PDE5 inhibitors in a single run: sildenafil, tadalafil, vardenafil and some of their analogues and impurities (trans-tadalafil [16]). A full validation using spiked placebo validation samples has been performed using the "total error" approach [31-38]. The robustness of the method has also been investigated. The precision and accuracy for the quantification of sildenafil citrate in Viagra ${ }^{\circledR}$ tablets has been compared to the HPLC method from the Viagra ${ }^{\circledR}$ registration dossier set as reference method. The method described here can be used as routine method for the analysis of PDE5-inhibitors and can be coupled in principle to a mass spectrometer for identity confirmation or structure elucidation.

The proposed method allows a faster and more environmental friendly high throughput analysis of both illegal and legal preparations containing PDE5-inhibitors. 


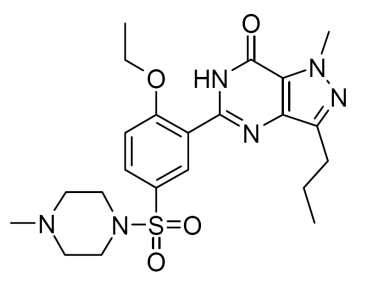

sildenafil

(present as citrate salt in Viagra $^{\circledR}$ )

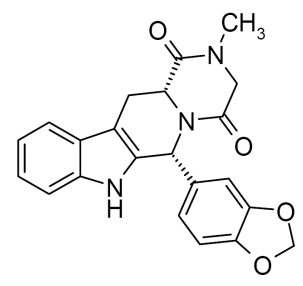

tadalafil $\left(\right.$ Cialis $\left.^{\circledR}\right)$

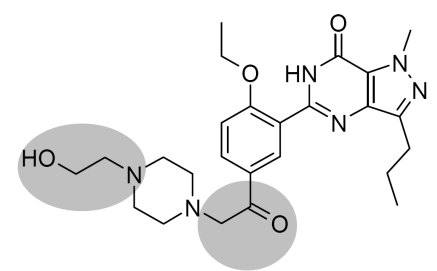

hydroxyacetildenafil (hydroxyhongdenafil)

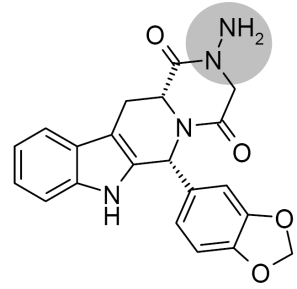

aminotadalafil

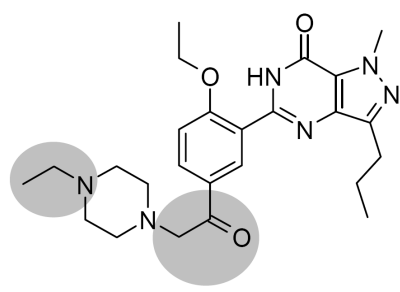

acetildenafil (hongdenafil)

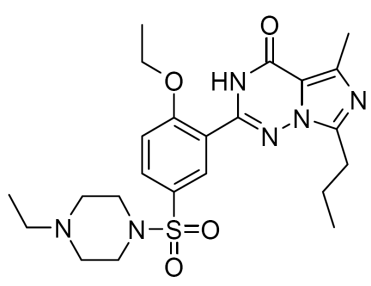

vardenafil

(present as hydrochloride salt in Levitra ${ }^{\circledR}$ )

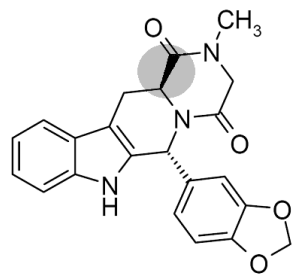

(-)-trans-Tadalafil

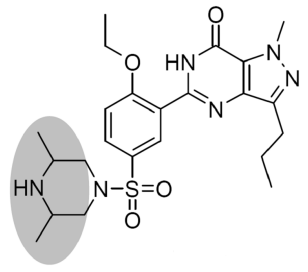

dimethylsildenafil

(aildenafil, methisosildenafil)

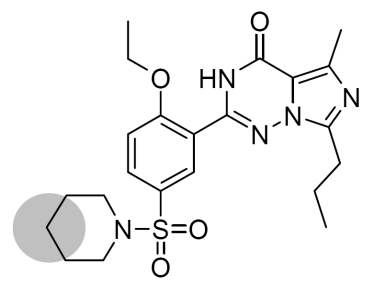

pseudovardenafil (piperidenafil)

Figure 1: Chemical structures of the studied compounds. The structural differences with the registered APIs are indicated in grey. (Reproduced from [2]). 


\section{Material and methods}

\subsection{Standards}

The reference standards of sildenafil citrate (batch 904958), tadalafil (batch RS0480) and vardenafil dihydrochloride trihydrate (batch BXR3835 R-1013-02B) were kindly provided by Pfizer SA/NV (Belgium), Eli Lilly SA/NV (Benelux) and Bayer SA/NV (Belgium), respectively. Reference standards of hydroxyacetildenafil (batches 1068-005A2 and 1068-013A2), acetildenafil (batch 1046-011A2), dimethylsildenafil (batch 1035-122A1), aminotadalafil (batch 1034-001A1) and pseudovardenafil (batch 1070-002A2) were purchased from TLC Pharmachem (Ontario, Canada).

\subsection{Samples}

Pfizer SA/NV (Belgium) kindly provided one batch of each different dosage of Viagra ${ }^{\circledR}$ (25 $\mathrm{mg}, 50 \mathrm{mg}, 100 \mathrm{mg}$ ). Two other batches of each dosage were purchased in a local pharmacy in Belgium.

\subsection{Reagents}

HPLC-grade acetonitrile was purchased from Biosolve (Valkenswaard, The Netherlands), formic acid and sodium hydroxide were obtained from VWR International (Leuven, Belgium) and ammonia solution $25 \%$ was purchased from Merck (Darmstadt, Germany). Trifluoroacetic acid was purchased from Sigma Aldrich (Saint-Louis, USA). The water used was produced by a milliQ-Gradient A10 system (Millipore, Billerica, USA). The herbal matrix used to realize the validation samples comes from a placebo dietary supplement received for PDE5 inhibitors screening.

\subsection{Sample preparation}

\subsubsection{Preparation of standards}

According to their absorbance, the substances were divided into two groups. Group 1 contains hydroxyacetildenafil, acetildenafil and tadalafil. Stock solutions of each compound of group 1 were prepared in double, diluting $10.0 \mathrm{mg}$ of pure substance (basic form) with 50.0 $\mathrm{ml}$ of a mixture of $\mathrm{H}_{2} \mathrm{O} / \mathrm{ACN}(50: 50, \mathrm{v} / \mathrm{v})$ (final concentration of $0.2 \mathrm{mg} \mathrm{mL}^{-1}$ of the basic form) The second group contains vardenafil, sildenafil, dimethylsildenafil, aminotadalafil and 
pseudovardenafil. Stock solutions of each compound of group 2 were prepared in double diluting $30.0 \mathrm{mg}$ of pure substance (basic form) with $50.0 \mathrm{ml}$ of a mixture of $\mathrm{H}_{2} \mathrm{O} / \mathrm{ACN}$ (50:50, $\mathrm{v} / \mathrm{v}$ ) (final concentration of $0.6 \mathrm{mg} \mathrm{mL}^{-1}$ of the basic form).

Calibration standards were then prepared by diluting the stock solutions to obtain the concentrations indicated in Table 1. All solutions were prepared in a mixture of $\mathrm{H}_{2} \mathrm{O} / \mathrm{ACN}$ $(50: 50, v / v)$.

Table 1: Concentrations of the calibration standards and the validation samples. These concentrations are based on the basic form of each compound.

\begin{tabular}{|c|c|c|c|c|} 
concentration levels & $\begin{array}{c}\text { calibration } \\
\text { standards group 1 }\end{array}$ & $\begin{array}{c}\text { calibration } \\
\text { standards group 2 }\end{array}$ & $\begin{array}{c}\text { validation samples } \\
\text { group 1 }\end{array}$ & $\begin{array}{c}\text { validation samples } \\
\text { group 2 }\end{array}$ \\
\hline 1 & $3 \mu \mathrm{g} / \mathrm{ml}$ & $9 \mu \mathrm{g} / \mathrm{ml}$ & $6 \mu \mathrm{g} / \mathrm{ml}$ & $18 \mu \mathrm{g} / \mathrm{ml}$ \\
2 & $10 \mu \mathrm{g} / \mathrm{ml}$ & $30 \mu \mathrm{g} / \mathrm{ml}$ & $12 \mu \mathrm{g} / \mathrm{ml}$ & $36 \mu \mathrm{g} / \mathrm{ml}$ \\
3 & $12 \mu \mathrm{g} / \mathrm{ml}$ & $36 \mu \mathrm{g} / \mathrm{ml}$ & $24 \mu \mathrm{g} / \mathrm{ml}$ & $72 \mu \mathrm{g} / \mathrm{ml}$ \\
4 & $14 \mu \mathrm{g} / \mathrm{ml}$ & $42 \mu \mathrm{g} / \mathrm{ml}$ & \\
5 & $32 \mu \mathrm{g} / \mathrm{ml}$ & $96 \mu \mathrm{g} / \mathrm{ml}$ &
\end{tabular}

\subsubsection{Preparation of spiked placebo validation samples}

The samples stock solutions were prepared the same way as the reference standards with the addition of $200 \mathrm{mg}$ herbal matrix to the pure substances. These solutions were magnetically stirred for 30 minutes, sonicated during 10 minutes and diluted to obtain the three concentration levels presented in Table 1 . These levels were chosen with a ratio $0.5 / 1 / 2$ to cover a large concentration range and to take into account the differences in concentration of the approved medicines. These final solutions were filtered with $0.2 \mu \mathrm{m}$ PTFE filters before injection.

\subsubsection{Preparation of samples for the comparison of methods}

Five tablets of each dosage form of different batches of Viagra ${ }^{\circledR}$ samples were pulverised. An amount of the pulverised tablets of $25 \mathrm{mg}, 50 \mathrm{mg}$ and $100 \mathrm{mg}$ was accurately weighed and diluted in a mixture of $\mathrm{H}_{2} \mathrm{O} / \mathrm{ACN}(50: 50, \mathrm{v} / \mathrm{v})$ to obtain the concentration levels 1,2 and 3 respectively. Concentrations of sildenafil at the levels 1,2 and 3 were $16 \mu \mathrm{g} \mathrm{m}^{-1}, 36 \mu \mathrm{gL}^{-1}$ and $72 \mu \mathrm{g} \mathrm{mL}{ }^{-1}$, respectively. Three different samples were weighed daily for each concentration level and were analysed three times per day for seven consecutive days (see section 3.3.). 


\subsection{Equipment and chromatographic conditions}

The HPLC experiments were performed on an Alliance 2690 HPLC system (Waters, Milford, USA) coupled to a 996 PDA detector (Waters). Data acquisition and treatment were performed with the Empower2 software (Waters).

The method optimisation and validation were performed on an Acquity UPLC ${ }^{T M}$ system (Waters). This system is composed of a binary solvent manager, a sample manager and a PDA detector. Data acquisition and treatment were also performed with the Empower2 software (Waters).

The initial method was developed in HPLC with a XTerra ${ }^{\mathrm{TM}} \mathrm{RP} 18(150 \mathrm{~mm} \times 4.6 \mathrm{~mm}, 5 \mu \mathrm{m}$ particle size) column (Waters). The optimisation and validation of the UHPLC gradient were performed on an Acquity ${ }^{\mathrm{TM}} \mathrm{BEH}$ Shield RP18 (100 mm x $2.1 \mathrm{~mm}, 1.7 \mu \mathrm{m}$ particle size) column. Mobile phase A consisted of a $10 \mathrm{mM}$ ammonium formate buffer $(\mathrm{pH} 3.5)$ and mobile phase $B$ was acetonitrile. The gradient conditions are presented in Tables 2 and 3. After each injection, the systems were reconditioned for $10 \mathrm{~min}$ for HPLC and $4 \mathrm{~min}$ for UHPLC (Ultra High Pressure Liquid Chromatography).

The quantitative results of the developed UHPLC method were compared to the results obtained with the reference method used in our lab for the assay of the Viagra ${ }^{\circledR}$ samples. For confidentiality reasons, the method is not described in this paper. The statistical comparison was performed using the method described by Kuttatharmakul et al. [29].

Table 2: HPLC and initial UHPLC gradient conditions. For more details see text section 2.5.

\begin{tabular}{|c|c|c|c|}
\hline \multicolumn{4}{|c|}{ HPLC conditions } \\
$\begin{array}{c}\text { Time } \\
(\mathrm{min})\end{array}$ & Flow rate (ml/min) & $\% \mathrm{~A}$ & $\% \mathrm{~B}$ \\
\hline 0 & 1.0 & 70 & 30 \\
5.0 & 1.0 & 65 & 35 \\
8.0 & 1.0 & 55 & 45 \\
9.0 & 1.0 & 20 & 80 \\
11.0 & 1.0 & 20 & 80 \\
12.0 & 1.0 & 70 & 30 \\
& & $20 \mu \mathrm{l}$ \\
& injection volume: & $30{ }^{\circ}$ &
\end{tabular}

\begin{tabular}{|c|c|c|c|}
\hline \multicolumn{4}{|c|}{ Initial UHPLC conditions } \\
\hline $\begin{array}{c}\text { Time } \\
(\mathrm{min})\end{array}$ & Flow rate (ml/min) & $\% \mathrm{~A}$ & $\% \mathrm{~B}$ \\
\hline 0 & 0.55 & 70 & 30 \\
2.2 & 0.55 & 65 & 35 \\
2.7 & 0.55 & 55 & 45 \\
2.9 & 0.55 & 20 & 80 \\
3.5 & 0.55 & 20 & 80 \\
4.0 & 0.55 & 70 & 30 \\
& & & \\
& injection volume: & $2.8 \mu \mathrm{l}$ \\
& Column temperature: & $40 \%$ \\
\end{tabular}


Table 3: Final UHPLC gradient conditions. For more details see text section 2.5.

\begin{tabular}{|c|c|c|c|}
$\begin{array}{c}\text { Time } \\
(\mathrm{min})\end{array}$ & Flow rate (ml/min) & $\% \mathrm{~A}$ & $\% \mathrm{~B}$ \\
\hline 0 & 0.55 & 75 & 25 \\
2.5 & 0.55 & 65 & 35 \\
3.5 & 0.55 & 55 & 45 \\
3.8 & 0.55 & 30 & 70 \\
4.5 & 0.55 & 30 & 70 \\
5.0 & 0.55 & 75 & 25 \\
& & & \\
& injection volume: & $1.5 \mu \mathrm{l}$ \\
& Column temperature: & $40{ }^{\circ} \mathrm{C}$
\end{tabular}

\subsection{Method transfer}

Figure 2 illustrates a chromatogram obtained by applying the initial HPLC gradient conditions presented in Table 2. These HPLC conditions were then adapted to obtain a UHPLC method by using the Waters Acquity UPLC ${ }^{T M}$ column calculator 1.0. This software optimizes the UHPLC parameters based on the HPLC conditions (for HPLC parameters see section 2.5) and column dimensions. The deduced conditions are presented in Table 2. The sub-2 micron polar-embedded stationary phase was chosen as the closest to the chemistry of the XTerra ${ }^{\mathrm{TM}}$ RP18 material column. These initial gradient conditions were modified to obtain a greater resolution between the peaks corresponding to vardenafil and acetildenafil which led to a more robust method. The final conditions are illustrated in Table 3. Figure 3 shows the corresponding chromatogram.

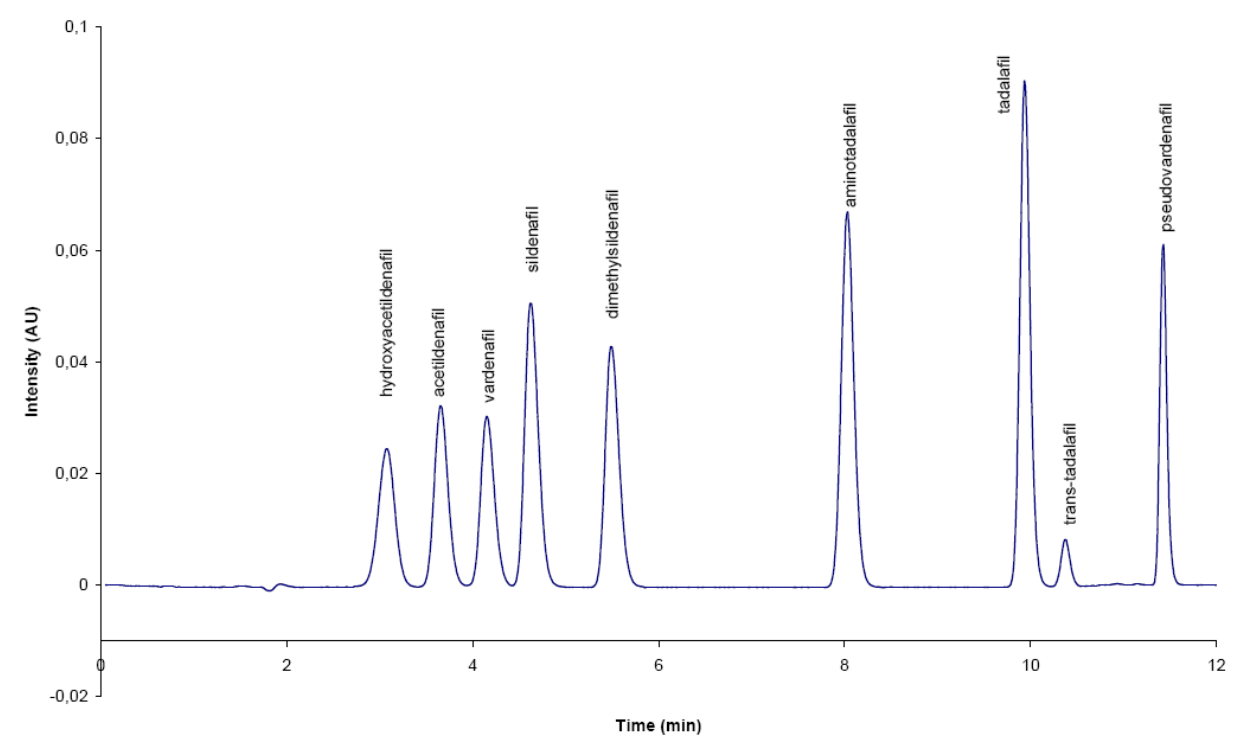

Figure 2: Typical chromatogram obtained by applying the gradient conditions of the HPLC method. 


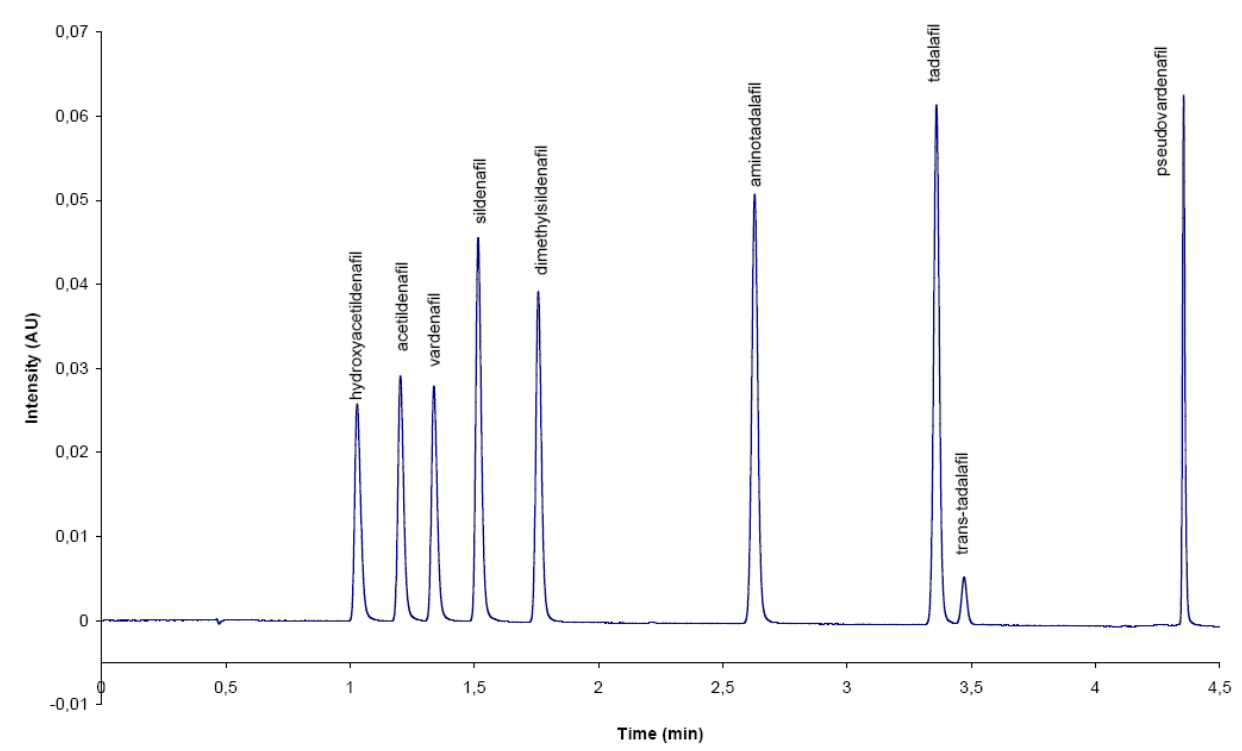

Figure 3: Typical chromatogram obtained by applying the final gradient conditions for the UHPLC method.

\subsection{System suitability testing}

System suitability testing was performed on the validation standard with the medium concentration. The acceptance criteria were a relative standard deviation (RSD) values for areas and retention times of less than $1.0 \%$ for 8 replicate injections.

\subsection{Method validation}

This method has been validated using the "total error" approach in accordance with the validation requirements in the ISO-17025 norm and the guidelines of the French Society of Pharmaceutical Sciences and Techniques (SFSTP) [30-38].

The "total error" approach adds the systematic error (bias or trueness) and the random error (precision or standard deviation) to know the difference between the observed result and the true value. Thus, the total error estimation of an analytical method shows the biggest errors that may be encountered while using it.

The goal of the validation of an analytical method is to guarantee that a chosen proportion (set at $95 \%$ during this study) of future samples will fall between the acceptance limits fixed a priori (for pharmaceutical specialties, $[-5 \% ; 5 \%]$ ). This proportion is evaluated by the $\beta$ expectation tolerance intervals (well described in [33]) at each concentration level studied. If the $\beta$-expectation tolerance intervals are comprised within the acceptance limits then the expected proportion of results will be included within these limits. 
The results obtained during the validation process are plotted with their $\beta$-expectation tolerance intervals and the acceptance limits, allowing a simple and fast evaluation of the present and future accuracy of the method.

\subsection{Robustness}

Robustness was performed on a standard solution prepared by mixing $25.0 \mathrm{ml}$ of the validation standard solution of groups 1 and 2 at the medium concentration.

The diastereoisomer of tadalafil, trans-tadalafil, was prepared for the robustness testing. Sodium hydroxide was added to a solution of tadalafil in a mixture of $\mathrm{H}_{2} \mathrm{O} / \mathrm{ACN}(50: 50 \mathrm{v} / \mathrm{v})$. After mixing for $30 \mathrm{~min}$, the solution was neutralized with trifluoroacetic acid. An aliquot of 3.0 $\mathrm{ml}$ of this solution was added to the $50.0 \mathrm{ml}$ standard solution used for the robustness test.

\subsection{Statistics}

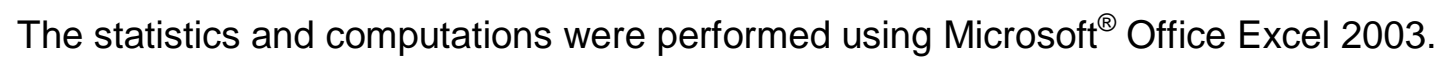

The choice of the calibration model and the validation of the Excel results were performed with the E-noval ${ }^{\mathrm{TM}}$ software V3.0 (Arlenda, Liège, Belgium).

\section{Results and discussion:}

\subsection{Method Development}

\subsubsection{Initial conditions selection}

The separation method has been developed in HPLC with UV detection in order to be applicable by a large amount of control laboratories. Acetonitrile was chosen as organic modifier as it causes less back pressure and better baseline stability than methanol. A $0.1 \%$ formic acid aqueous solution ( $\mathrm{pH}$ 2.8) was used as aqueous component of the mobile phase to be compatible with on-line mass spectrometry.

Initial HPLC conditions were a linear gradient starting from $5 \%$ acetonitrile to $100 \%$ in 27 min. The gradient time was calculated using the following equation considering $150 \times 4.6 \mathrm{~mm}$ column dimensions:

$$
\bar{k} \cong \frac{F \times t_{G}}{\Delta \phi \times V_{m} \times S}
$$


where $\bar{k}$ is the mean retention factor (here set at 4 ), $\mathrm{t}_{\mathrm{G}}$ is the gradient time (min), $\mathrm{F}$ is the flow rate $\left(\mathrm{ml} \mathrm{min}^{-1}\right), \Delta \phi$ is the difference between the final and initial percents of organic modifier divided by $100, V_{m}$ is the column dead volume $(\mathrm{ml})$ and $\mathrm{S}$ is a constant (equal to 4 for small molecules).

The presented gradient conditions were used on different stationary phases (results not shown). The best results were obtained with a $\mathrm{C}_{18}$ polar embedded stationary phase such as an XTerra ${ }^{\text {TM }}$ RP18.

During the optimization process, no satisfactory conditions were found with the $0.1 \%$ formic acid solution ( $\mathrm{pH}$ 2.8) as aqueous phase. The problem comes from the fact that vardenafil co-eluted with hydroxyacetildenafil before the start of the gradient. Indeed, at pH 2.8, the three basic nitrogens of vardenafil are ionised decreasing the retention of the molecule in reversed phase conditions. It was then decided to set the $\mathrm{pH}$ at 3.5 to deprotonate partially vardenafil (pKa values of $8.8,6.7$ and 3.4). This $\mathrm{pH}$ value was obtained using a $10 \mathrm{mM}$ ammonium formate buffer. The change of $\mathrm{pH}$ resulted in a higher retention of vardenafil. It was then possible to slightly adjust the gradient conditions to obtain the desired separation. These final gradient conditions are presented in Table 2.

\subsubsection{Method transfer}

The HPLC conditions were transferred to UHPLC as described in section 2.6. The calculated initial UHPLC gradient conditions were slightly modified to obtain a better separation. Especially for the two critical pairs: acetildenafil/vardenafil and tadalafil/trans-tadalafil. The final UHPLC conditions (shown in Table 3) were then validated.

\subsection{Method Validation}

\subsubsection{Selectivity}

The method selectivity was assessed by the constancy of the retention times and the UV spectrum of each component determined separately during the validation process.

\subsubsection{Response Function}

Several response functions were tested. They are the unweighted linear regression, the linear regression after mathematic transformations (log, square root), the weighted linear 
regression $\left(1 / X, 1 / X^{2}\right)$ and the weighted quadratic regression $\left(1 / X, 1 / X^{2}\right)$. The unweighted linear regression model was chosen since it gives comparable results with the more complicated calibration models tested.

\subsubsection{Linearity}

The linearity of the relationship between the measured and theoretical concentrations was investigated over the concentration range described in Table 1. The measured concentrations were back-calculated using the selected calibration model. Validation results for tadalafil were both computed with an in-house Excel template and the E-noval software. The results obtained with Excel were comparable with those obtained with E-noval. The linearity of the results is expressed by the coefficient of determination $\left(r^{2}\right)$. For the eight compounds the relationship was linear as the $r^{2}$ values were all $>0.99$ and the equation was close to $\mathrm{y}=\mathrm{x}$.

\subsubsection{Trueness, precision, accuracy and uncertainty assessment}

A statistical approach based on the "total error" profiles was applied to validate the method. All validation samples were analysed in triplicate for four consecutive days.

The concentrations were back-calculated using the calibration lines described in 2.4.1. These concentrations were used to determine the relative bias, the repeatability, the intermediate precision and the $\beta$-expectation tolerance intervals at the $95 \%$ probability level. The results are shown in Table 4.

The RSD values of repeatability and intermediate precision were inferior to $1 \%$ and $1.37 \%$, respectively. These values are said acceptable since their maximal Horwitz ratio is inferior to 0.5 [39] ( 0.251 for sildenafil in Viagra ${ }^{\circledR}, 0.249$ for tadalafil in Cialis ${ }^{\circledR}$ and 0.393 for vardenafil in Levitra $\left.^{\circledR}\right)$.

As the method will also be used for the analysis of registered medicines, the acceptance limits were set at $\pm 5 \%$. As shown in Figure 4 , the $\beta$-expectation tolerance intervals of each substance are within the acceptance limits with a probability of $95 \%$ except for the medium concentration level of acetildenafil and the highest concentration level of pseudovardenafil. However, the tolerance limits remain close to $5 \%$. 
Table 4: Trueness, precision, accuracy and uncertainty

\begin{tabular}{|c|c|c|c|c|c|c|c|c|c|}
\hline & $\begin{array}{c}\text { concentration } \\
\text { level }\end{array}$ & $\begin{array}{c}\text { hydroxy } \\
\text { acetildenafil }\end{array}$ & acetildenafil & vardenafil & sildenafil & $\begin{array}{l}\text { dimethyl } \\
\text { sildenafil }\end{array}$ & $\begin{array}{c}\text { amino } \\
\text { tadalafil }\end{array}$ & tadalafil & $\begin{array}{c}\text { pseudo } \\
\text { vardenafil }\end{array}$ \\
\hline \multicolumn{10}{|l|}{ trueness } \\
\hline \multirow{4}{*}{$\begin{array}{l}\text { relative bias (\%) } \\
\text { intra-assay precision }\end{array}$} & 1 & 0.30 & 1.02 & 0.33 & 0.68 & 1.38 & 0.97 & 0.29 & 1.31 \\
\hline & 2 & -0.31 & 0.59 & 0.28 & 0.38 & 0.62 & 0.58 & 0.37 & 1.21 \\
\hline & 3 & -1.48 & -0.04 & -0.11 & -0.10 & 0.05 & 0.24 & -0.24 & 0.71 \\
\hline & & & & & & & & & \\
\hline \multirow[b]{2}{*}{ repeatability (RSD\%) } & 1 & 0.55 & 0.39 & 0.66 & 0.38 & 0.44 & 0.48 & 0.54 & 0.35 \\
\hline & 2 & 0.49 & 0.23 & 0.43 & 0.27 & 0.26 & 0.34 & 0.34 & 0.26 \\
\hline$\frac{\text { between-assay }}{\text { precision }}$ & 3 & 0.26 & 0.17 & 0.51 & 0.40 & 0.45 & 0.43 & 0.15 & 0.46 \\
\hline \multirow{3}{*}{$\begin{array}{l}\text { intermediate precision } \\
\text { (RSD \%) }\end{array}$} & 1 & 1.37 & 0.50 & 1.10 & 0.38 & 0.52 & 0.78 & 0.64 & 0.80 \\
\hline & 2 & 1.24 & 0.24 & 0.55 & 0.47 & 0.31 & 0.51 & 0.41 & 0.51 \\
\hline & 3 & 1.00 & 0.31 & 0.82 & 0.66 & 0.64 & 0.79 & 0.77 & 0.76 \\
\hline \multicolumn{10}{|l|}{ accuracy } \\
\hline \multirow{3}{*}{$\begin{array}{l}\beta \text {-expectation tolerance } \\
\text { limits }(\%)\end{array}$} & 1 & {$[-3.85 ; 4.45]$} & {$[-0.27 ; 2.30]$} & {$[-3.01 ; 3.68]$} & {$[-0.22 ; 1.58]$} & {$[0.08 ; 2.67]$} & {$[-1.25 ; 3.19]$} & {$[-1.22 ; 1.79]$} & {$[-1.52 ; 4.14]$} \\
\hline & 2 & {$[-4.03 ; 3.42]$} & {$[0.04 ; 1.14]$} & {$[-1.11 ; 1.68]$} & {$[-1.06 ; 1.82]$} & {$[-0.14 ; 1.39]$} & {$[-0.85 ; 2.02]$} & {$[-0.60 ; 1.33]$} & {$[-0.36 ; 2.78]$} \\
\hline & 3 & {$[-4.47 ; 1.52]$} & {$[-0.98 ; 0.91]$} & {$[-2.39 ; 2.18]$} & {$[-1.94 ; 1.74]$} & {$[-1.64 ; 1.74]$} & {$[-2.17 ; 2.65]$} & {$[-2.95 ; 2.48]$} & {$[-1.62 ; 3.04]$} \\
\hline \multicolumn{10}{|l|}{ uncertainty } \\
\hline \multirow{3}{*}{$\begin{array}{l}\text { relative expanded } \\
\text { uncertainty }(\%)\end{array}$} & 1 & 2.99 & 1.09 & 2.41 & 0.81 & 1.12 & 1.73 & 1.35 & 1.78 \\
\hline & 2 & 2.67 & 0.50 & 1.18 & 1.04 & 0.66 & 1.12 & 0.87 & 1.13 \\
\hline & 3 & 2.16 & 0.68 & 1.78 & 1.43 & 1.38 & 1.74 & 1.71 & 1.68 \\
\hline
\end{tabular}



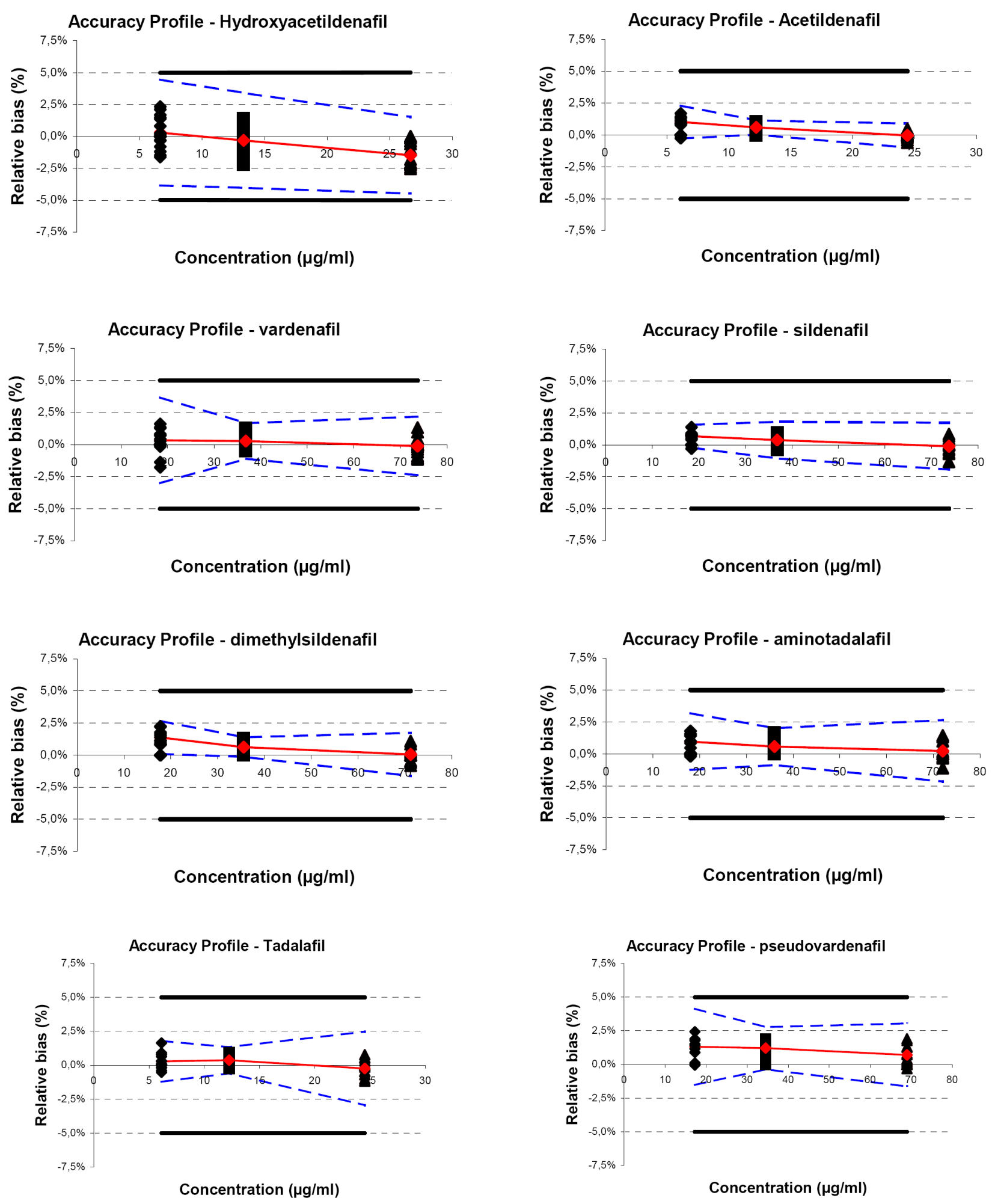

Figure 4: Accuracy profiles of the studied compounds. The plain line is the relative bias, the dashed lines are the $\beta$-expectation tolerance limits $(\beta=95 \%)$ and the bold plain lines are the acceptance limits set at $5 \%$. The dots represent the relative back-calculated concentrations of the validation samples, plotted with regards to their target concentration. 
The uncertainty of measurement [35] characterises the dispersion of the values that could reasonably be attributed to the analyte. The expanded uncertainty represents the interval around the results where the unknown true value can be observed at a confidence level of 95 $\%$. Relative expanded uncertainties (\%) are obtained by dividing the corresponding expanded uncertainty by the corresponding concentration. The values are presented in Table 4 and are all below $3 \%$.

\subsubsection{Robustness}

Robustness is the evaluation of the constancy of the results when variables inherent to the method of analysis are varied deliberately.

The test was performed by a three-factor three-level full factorial design [40]. The factors were the flow rate of the mobile phase, the column temperature and the $\mathrm{pH}$ of the ammonium formate buffer. The response was the resolution between tadalafil and trans-tadalafil (critical pair). The values were chosen to cover typical errors that could occur. Table 5 shows the experimental design. Each experiment was performed in triplicate and the mean value was used for computations.

The effect of each factor was calculated for its signification at $5 \%$ level using an ANOVA analysis. The regression is meaningful since the value of $\mathrm{R}^{2}$ is $99.96 \%$. From the ANOVA table, it can be seen that only the $\mathrm{pH}$ and the flow rate have a significant effect on the resolution ( $p$-values $<0.0001$ ). However this effect is still very small since the resolution varies between 2.64 and 2.79 .

The method can be considered as robust since only a very small change in resolution occurs. 
Table 5: 3-factors 3-levels full factorial design performed for robustness evaluation.

\begin{tabular}{|c|c|c|c|}
\hline $\mathrm{pH}$ & temperature $\left({ }^{\circ} \mathrm{C}\right)$ & flow (ml/min) & Resolution tadala fil/trans-tadalafil \\
\hline 3.4 & 39 & 0.50 & 2.74 \\
\hline 3.4 & 39 & 0.55 & 2.73 \\
\hline 3.4 & 39 & 0.60 & 2.68 \\
\hline 3.4 & 40 & 0.50 & 2.75 \\
\hline 3.4 & 40 & 0.55 & 2.71 \\
\hline 3.4 & 40 & 0.60 & 2.66 \\
\hline 3.4 & 41 & 0.50 & 2.75 \\
\hline 3.4 & 41 & 0.55 & 2.72 \\
\hline 3.4 & 41 & 0.60 & 2.68 \\
\hline 3.5 & 39 & 0.50 & 2.75 \\
\hline 3.5 & 39 & 0.55 & 2.69 \\
\hline 3.5 & 39 & 0.60 & 2.64 \\
\hline 3.5 & 40 & 0.50 & 2.73 \\
\hline 3.5 & 40 & 0.55 & 2.70 \\
\hline 3.5 & 40 & 0.60 & 2.65 \\
\hline 3.5 & 41 & 0.50 & 2.73 \\
\hline 3.5 & 41 & 0.55 & 2.71 \\
\hline 3.5 & 41 & 0.60 & 2.67 \\
\hline 3.6 & 39 & 0.50 & 2.77 \\
\hline 3.6 & 39 & 0.55 & 2.76 \\
\hline 3.6 & 39 & 0.60 & 2.70 \\
\hline 3.6 & 40 & 0.50 & 2.78 \\
\hline 3.6 & 40 & 0.55 & 2.76 \\
\hline 3.6 & 40 & 0.60 & 2.71 \\
\hline 3.6 & 41 & 0.50 & 2.79 \\
\hline 3.6 & 41 & 0.55 & 2.76 \\
\hline 3.6 & 41 & 0.60 & 2.69 \\
\hline
\end{tabular}

\subsection{Method comparison}

The method was compared with a validated method considered as reference method.

The samples were prepared as described in section 2.4.3. and analysed three times per day for seven consecutive days by applying UHPLC and HPLC methods. The minimum of days required and the comparison were performed according to the method described by Kuttatharmmakul et al. [29]. Results are shown in Table 6.

The variances of both methods were compared using a two-sided F-test at a significance level $\alpha=0.05$ ( 6 degrees of freedom for both methods). The variances were not shown as statistically different since all F-statistics are below the critical value of 5.82 . 
Table 6: Results of the comparison tests

\begin{tabular}{c|c|c|c|} 
& Concentration level 1 & Concentration level 2 & Concentration level 3 \\
\hline $\begin{array}{c}\text { variance of the reference } \\
\text { method }\left(\sigma^{2} \mathrm{~A}\right)\end{array}$ & 0.429 & 0.113 & 2.825 \\
$\begin{array}{c}\text { variance of the new } \\
\text { method }\left(\sigma^{2} \mathrm{~B}\right)\end{array}$ & 0.516 & 0.091 & 2.624 \\
$\begin{array}{c}\text { t-statistics for bias } \\
\text { between both methods } \\
\begin{array}{c}\text { interval hypothesis test } \\
(\%)\end{array}\end{array}$ & 0.14 & 1.22 & 1.02 \\
\hline
\end{tabular}

The bias between the methods was tested using a paired t-test comparing the grand means of both methods. The differences between the grand means was considered statistically non significant since their value is below the critical value of $2.18(\alpha / 2=0.025,12$ degrees of freedom for both methods).

The interval hypothesis test described by Hartman et al. [41] was performed to be sure of not accepting a new method with an unacceptable bias. For the interval hypothesis test, a bias of $2 \%$ was said to be acceptable. As can be seen in Table 6, these requirements are fulfilled for the concentration levels 1 and 2 . However, the highest concentration level has an unacceptable bias which means that the HPLC method is best suited at that concentration for the assay of sildenafil citrate in Viagra ${ }^{\circledR}$ tablets.

A Bland and Altman plot [42] is shown in Figure 5. This plot represents the relative differences (\%) between the HPLC reference method and the new UHPLC method against the average content of API (\%) for the three concentration levels. As one can see, $95 \%$ of the relative differences are comprised between $[-2,61 \% ; 1,18 \%]$. Those results are comprised between the maximum acceptable relative differences between the two methods set at $\pm 5 \%$. It is finally concluded that the two methods gave comparable results. 


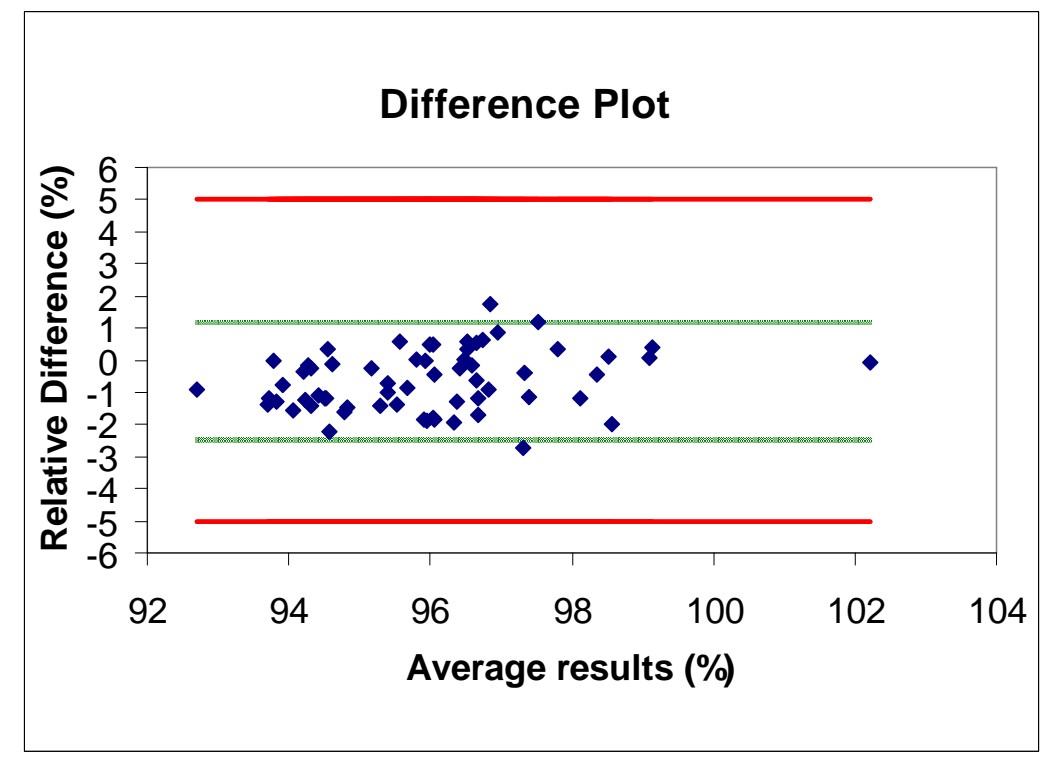

Figure 5: Bland and Altman plot of the relative differences (\%) of the results obtained by the HPLC reference method and the new UHPLC method against the average content of API (\%) for the three concentration levels results of the two methods. Dashed lines: 95\% agreement limits of the relative differences; Continuous lines: maximum acceptable relative difference between the two methods set at $\pm 5 \%$; Dots: relative differences.

\section{Conclusion}

This paper describes for the first time a fully validated method which enables the detection and the quantification of authorised phosphodiesterase type 5 inhibitors and some of their analogues in less than 4.5 minutes. This rapidity associated to a low flow rate permits the analysis of a large number of samples with a reduced cost and associated solvent consumption.

The main problem with counterfeit medicines is that their chemical composition is unknown. This is why they represent a real danger for public health. The method permits the detection of all PDE5 inhibitors even other new structurally related substances as it covers a wide range of polarity. The elucidation of structures and the confirmation of identity may be performed by UHPLC-MS systems since the mobile phase is compatible.

The method has already been applied to real samples and showed no interference with common other substances present as yohimbine (retention time of $0.77 \mathrm{~min}$ ) and caffeine (retention time of $0.57 \mathrm{~min}$ ).

An important point in counterfeit medicines detection is the cost of the UHPLC system and its applicability in developing countries. However, this is not really a problem since PDE5 inhibitors are mainly sold in rich and industrialised countries. 


\section{References}

[1] A. Deisingh, Analyst 130 (2005) 271

[2] B.J. Venhuis, D.M. Barends, M.E. Zwaagstra, D. de Kaste, Recent developments in counterfeit and imitations of Viagra, Cialis and Levitra, RIVM Report 370030001/2007, Bilthoven, 2007

[3] H.M. Lee, C.S. Kim, Y.M. Jang, S.W. Kwon, B.J. Lee, J. Pharm. Biomed. Anal. 54 (2011) 491

[4] S. Singh, B. Prasad, A. Savaliya, R. Shah, V. Gohil, A. Kaur, Trends Analyt. Chem. 28 (2009) 13-

[5] S. Gratz, M. Zeller, D. Mincey, C. Flurer, J. Pharm. Biomed. Anal. 50 (2009) 228

[6] J. Reepmeyer, D.A. d'Avignon, J. Pharm. Biomed. Anal. 49 (2009) 145

[7] M.C. Lin, Y.C. Liu, J.H. Lin, J. Food. Drug. Anal. 14 (2006) 260

[8] K.C. Lai, Y.C. Liu, M.C. Tseng, J.H. Lin, J. Food. Drug. Anal. 14 (2006) 19

[9] P. Hou, P. Zou, M.Y. Low, E. Chan, H.L. Koh, Food. Addit. Contam. Part A 23 (2006) 870

[10] C. Shin, M. Hong, D. Kim, Y. Lim, Magn. Reson. Chem. 42 (2004) 1060

[11] L. Blok-Tip, B. Zomer, F. Bakker, K.D. Hartog, M. Hamzink, J. ten Hove, M. Vredenbregt, D. de Kaste, Addit. Contam. Part A 21 (2004) 737

[12] V. Nagaraju, D. Sreenath, J. Tirumala Rao, R. Nageswara Rao, Anal. Sci. 19 (2003) 1007

[13] N.D. Dinseh, B.K. Vishukumar, P. Nagaraja, N.M. Made Gowda, K.S. Rangappa, J. Pharm. Biomed. Anal. 29 (2002) 743

[14] N. Daragmeh, M. Al-Omari, A.A. Badwan, A.M.Y. Jaber, J. Pharm. Biomed. Anal. 25(2001) 483

[15] A. Häberli, P. Girard, M.Y. Low, X. Gei, J. Pharm. Biomed. Anal. 53 (2010) 24

[16] B.J. Venhuis, G. Zomer, M.J. Vredenbregt, D. de Kaste, J. Pharm. Biomed. Anal. 51 (2010) 723

[17] H.Y. Aboul-Enein, I. Ali, Talanta 65 (2005), 276

[18] J.C. Reepmeyer, J.T. Woodruff, J. Chromatogr. A 1125 (2006) 67

[19] D. De Orsi, M. Pellegrini, E. Marchei, P. Nebuloni, B. Gallinella, G. Scaravelli, A. Martufi, L. Gagliardi, S. Pichini, J. Pharm. Biomed. Anal. 50 (2009) 362

[20] C.M. Gryniewicz, J.C. Reepmeyr, J.F. Kauffman, L.F. Buhse, J. Pharm. Biomed. Anal. 49 (2009) 601

[21] A.A. Savalyia, R.P. Shah, B. Prasad, S. Singh, J. Pharm. Biomed. Anal. 52 (2010) 406

[22] D.M. Choi, S. Park, T.H. Yoon, H.K. Jeong, J.S. Pyo, J. Park, D. Kim, S.W. Kwon, J. AOAC Int. 91 (2008) 580 
[23] H.J. Park, H.K. Jeong, M.I. Chang, M.H. Im, J.Y. Jeong, D.M. Choi, K. Park, M.K. Hong, J. Youm, S.B. Han, D.J. Kim, J.H. Park, S.W. Kwon, Food. Addit. Contam. (24 (2007) 122

[24] S.R. Gratz, B.M. Gamble, R.A. Flurer, Rapid Commun. Mass. Spectrom. 20 (2006) 2317

[25] P. Zou, S.S.-Y. Oh, P. Hou, M.-Y. Low, H.-L. Koh, J. Chromatogr. A 1104 (2006) 113

[26] X. Zhu, S. Xiao, B. Chen, F. Zhang, S. Yao, Z. Wan, D. Yang, H. Han, J. Chromatogr. A 1066 (2005) 89

[27] N. Fleshner, M. Harvey, H. Adomat, C. Wood, A. Eberding, K. Hersey, E. Guns, J. Urol. 174 (2005) 636

[28] S.R. Gratz, C.L. Flurer, K.A. Wolnik, J. Pharm. Biomed. Anal. 36 (2004) 525

[29] S. Kuttatharmmakul, D.L. Massart, J. Smeyers-Verbeke, Anal. Chim. Acta 391 (1999)

203

[30] ISO/IEC 17025, General requirements for the competence of testing and calibration laboratories, ISO, Geneva, 2005

[31] Ph. Hubert, J.J. Nguyen-Huu, B. Boulanger, E. Chapuzet, P. Chiap, N. Cohen, P.A.

Compagnon, W. Dewé, M. Feinberg, M. Lallier, M. Laurentie, N. Mercier, G. Muzard, C.

Nivet, L. Valat, J. Pharm. Biomed. Anal. 36 (2004) 579

[32] Ph. Hubert, J.J. Nguyen-Huu, B. Boulanger, E. Chapuzet, P. Chiap, N. Cohen, P.A.

Compagnon, W. Dewé, M. Feinberg, M. Lallier, M. Laurentie, N. Mercier, G. Muzard, C.

Nivet, L. Valat, E. Rozet, J. Pharm. Biomed. Anal. 45 (2007) 70

[33] Ph. Hubert, J.J. Nguyen-Huu, B. Boulanger, E. Chapuzet, N. Cohen, P.A. Compagnon, W. Dewé, M. Feinberg, M. Laurentie, N. Mercier, G. Muzard, L. Valat, E. Rozet, J. Pharm.

Biomed. Anal. 45 (2007) 82

[34] Ph. Hubert, J.J. Nguyen-Huu, B. Boulanger, E. Chapuzet, N. Cohen, P.A. Compagnon, W. Dewé, M. Feinberg, M. Laurentie, N. Mercier, G. Muzard, L. Valat, E. Rozet, J. Pharm. Biomed. Anal. 48 (2008) 760

[35] M. Feinberg, B. Boulanger, W. Dewé, Ph Hubert, Anal. Bioanal. Chem. 380(2004) 502

[36] M. Feinberg, J. Chromatogr. A 1158 (2007) 174

[37] E. Rozet, A. Ceccato, C. Hubert, E. Ziemons, R. Oprean, S. Rudaz, B. Boulanger, Ph. Hubert, J. Chromatogr. A 1158 (2007) 111

[38] P. Araujo, J. Chromatogr. B 877 (2009) 2224

[39] Horwitz W., Albert R., J. AOAC Int. 89 (2006) 1095

[40] D.L. Massart, B.G.M. Vandeginste, L.M.C. Buydens, S. De Jong, P.J. Lewi, J. SmeyersVerbeke, Handbook of Chemometrics and Qualimetrics: Part A, Elsevier Science, Amsterdam, 1997

[41] C. Hartmann, J. Smeyers-Verbeke, W. Penninckx, Y. Vanderheyden, P. Vankeerberghen, D.L. Massart, Anal. Chem. 67 (1995) 4491

[42] J.M. Bland, D.G. Altman, Lancet (1986) 307 